\title{
Proposal of a Method for the Implementation of Industry 4.0 - Aircraft Final Assembly Domain
}

\author{
Alexandre Leite Junior, Gléverson Fabner Condé Lemos, Luís Gonzaga Trabasso \\ Department of Aeronautical and Mechanical Engineering, Instituto Tecnológico de Aeronáutica (ITA), São José dos \\ Campos, São Paulo/Brazil \\ E-mail: alexandreleitejr@gmail.com, gleverson.lemos@engenharia.ufff.br, gonzaga@ita.br
}

\begin{abstract}
The present work proposes a method to guide companies in a gradual implementation of Industry 4.0 based on the best practices identified in the scientific literature and customised to their contexts. In this sense, nine methods developed by other authors in the literature (ACATECH, $\mathrm{PwC}$, Capgemini etc.) were analysed comparatively in order to identify opportunities to build an improved solution. Thus, the best practices identified were brought together and integrated on a new method which had each of its stages systematised. Furthermore, as a way of exemplifying its usage, the proposed method has been represented in the Aircraft Final Assembly domain based on information collected from the literature and through interviews conducted with professionals of this area. At the end, the novel method has been evaluated in two ways: through a comparative analysis with the proposals of other authors and through a value perception survey applied to professionals from the industry and academy, related to the Industry 4.0 and innovation field within the aeronautical domain. Accordingly, this paper presents a comparative analysis of nine methods for the implementation of Industry 4.0 and provides a more complete solution based on the best practices identified in the scientific literature. In addition, it systematises a procedure for the elaboration of a customised Industry 4.0 Maturity Scale, presents the macro process mapping of a general Aircraft Final Assembly area and an Industry 4.0 Maturity Scale designed and customised for the Aircraft Final Assembly domain.
\end{abstract}

Keywords: Aircraft Manufacturing, Advanced Manufacturing, Industry 4.0 Maturity Scale

\section{Introduction}

According to Schuh et al. [1] Industry 4.0 (I4.0) is a new concept of the market characterised by the wide integration of information, communication and Cyber-Physical Systems (CPS) in the industrial environment. In general, it denotes an unprecedented transformation in terms of productivity, flexibility and agility; stimulating the efficient and sustainable use of limited resources, profitable production of highly customised products and the emergence of new business models in the market. In addition, some authors [1] [2] agree that Industry 4.0 's most significant contribution is to transform companies into fast-learning organisations with agile interactions, capable of continuous adaptation to changing environments.

However, Schuh et al. [1], Porter and Heppelmann [3] emphasise that the phenomenon of Industry 4.0 is still a novelty without clear boundaries because it is not standardised and well disseminated in the market yet. Pessl et al. [4] consider that this is mainly due to the following obstacles: high investment costs, lack of transparency regarding potential benefits and fears related to changes in the organisational structure and the Information Technology security.
Thus, to obtain the benefits of I4.0, companies have to adopt a systematic and gradual plan of implementation, based on its market strategy and its structure as a whole. [1] [5] [6] For this purpose, some authors have proposed Methods for the Implementation of Industry 4.0 (MII4.0), in order to guide companies in this endeavor.

However, none of the methods found in the literature summarises all the best practices presented by them individually. Moreover, the related authors do not systematise how companies with specific characteristics - like from the aeronautical industry - could create the vision of I4.0 projected to their particular context, so that the deployment project is properly customised.

In this sense, the present work analyses, proposes and evaluates a more complete, flexible and customised MII4.0, in order to provide a scientifically based solution with a practical approach. The proposal is presented and has its structure detailed (with the description of its stages and decision points).

As a way of complementing the work, it was represented in the aeronautical context (more specifically, in the final assembly area), which is a very fertile environment for this 
subject, due to its demanding levels of quality, flexibility, reliability, performance and cutting-edge technologies. [7]

Considering the subject exposed, the objective of this work was to propose a Method for the Implementation of Industry 4.0 (MII4.0) that met the best practices identified in the literature and could be customised to its application context, representing it in the Aircraft Final Assembly area.

\section{Industry 4.0}

The fourth industrial revolution refers to a new global wave that aims to seamlessly combine manufacturing, automation and Information \& Communication Technology (ICT) into a vertical network within an organisation by connecting two or more of these organisations in a horizontal chain. These connected systems (also defined as CPS) are fused - blurring the lines that divide the physical and digital domains - being able to interact with each other using standard Internet-based Protocols, allowing data analysis, failure prediction and selfconfiguration in order to adapt to changes. [5] [6] [8] [9] [10] [11]

The concept of CPS indicates that physical production plants are connected to each other in an open network. This enables an autonomous and integrated value chain, where data and information travel without barriers among the different internal sectors of the company, as well as among the external stakeholders involved in the process. The goal is to create an integrated, flexible, efficient, transparent and optimised production flow. [5] [6] [8] [9] [10] [11]

The great advantage of this revolution, for Schuh et al. [1], is how quickly the companies will be able to react to variations in the value chain by: (1) having an instant insight of any new circumstance (real-time capability and systems integration); (2) accurately analysing information, based on reliable data (Big Data Analytics for known hypotheses and Machine Learning/Artificial Intelligence for new contexts); (3) making decisions with precision and speed (decision support systems / automated decision making); and finally (4) acting seamlessly and optimally (vertical / horizontal process / systems integration and CPS).

In addition, Rüßmann et al. [10] and Bloem et al. [12] highlight gains in productivity, cost decrease, inventory reduction and increased customisation due to increased agility and intelligence generated thanks to improvement in Machine-to-Machine (M2M) communication, HumanMachine Interaction (HMI) and predictive maintenance.

Specifically in the Aerospace, Defense and Security sector, the expected cost reduction to be obtained from I4.0 deployment is $3.7 \%$ per year. This might explain why executives of this market intend to invest $5 \%$ of its annual revenue in digital operations solutions, over the next five years. [13]

\subsection{Industry 4.0 in aeronautics}

The aeronautical industry is characterised by low volumes of products, with a restricted and specific market and a complex manufacturing process. [14]
The latter can be broadly divided into five distinct stages: (1) fabrication of primary parts, through mechanical forming, machining and composite lamination processes. (2) Fabrication of elementary subsets of wiring, pipes and welded parts. (3) Assembly of parts by the grouping of primary parts, producing panels, fairing, stringers, ribs etc. (4) Assembly of segments by joining the fabricated / assembled parts (from the initial three phases), resulting in the half-wings, empennages and fuselage sections. (5) Last stage, where the aircraft parts are painted, pre-equipped / equipped with aircraft systems (Air-Management-Systems, hydraulics, landing gear, flight controls etc.), finishing when the aircraft passes to the flight preparation and delivery to the client. [15]

The complex manufacturing in addition to the low production cadence results in weak automation and significant labour along the processes, achieving up to $80 \%$ of total costs. For this reason, the key contribution of I4.0 in the aeronautical context is supporting human workers with digital enhanced solutions to improve company results. [8] [14]

In this work, a focus was given to the final assembly area, which is located in the last stages (after structural assembly and before flight preparation), being characterised by activities of high diversity, complexity, customisation and with the use of specific technologies, showing a high potential for progress with the Advanced Manufacturing.

In the literature, several authors [9] [10] [15] [16] have listed nine key technologies that are enabling the introduction of I4.0 (even though there are others being explored). Many of them are already being used in some contexts, but integrated, they will be able to transform aeronautics around the world.

One of those technologies, capable of significantly transforming aircraft manufacturing, is the Internet of Things (IoT). Using an IoT platform to connect workers and other I4.0 solutions (like Augmented Reality) could make processes much quicker and reliable, by allowing critical information to flow seamlessly. For instance, an employee could use a tablet or smart glasses to scan a specific part of the airplane and automatically receive (from a local Cloud) the precise data related to installation procedure, needed parts and other technical information. Still, this information could be sent to a robotic tool, which could perform the task. [8] [14] [17]

On another situation, IoT could be used to locate tools on the shop floor and track its usage. This could validate if tools are only being handled by authorised and trained people (increasing people safety and product security) and monitor usage data, based on assembly specifications (reducing mistakes, avoiding the burden of regulation compliance and reducing costs with quality inspections). [8] [17]

Further contributions of I4.0 can come from Horizontal and Vertical System Integration (HVSI), where Information Technology/Operational Technology (IT/OT) infrastructure will have a much stronger integration among internal departments and beyond the company boundaries (suppliers, clients, third parties etc.). This is specifically beneficial for the aeronautical sector, since its supply chain is based on a complex network (with a large number of actors, specific 
technologies providers, traffic of ultra-confidential data etc.). [8] [14]

So that the HVSI is enabled, Cloud solutions (that are already present in several enterprises) will be significantly improved to allow a greater data traffic (inside and outside the company), with a minimal reaction time and reliable transmission. [10]

Due to its low volume of production and high number of different tasks, the aircraft industry has been limited in the application of conventional automation. With substantial enhancements in terms of safety, interaction and autonomy; Advanced Robotics intends to enable a collaborative environment where humans and robots can work together, sharing tasks in an open and fenceless shop floor. This new advent allows processes do be more flexible and optimised, by delegating potentially risky, repetitive, of difficult access, not ergonomic or precise activities to robots; allowing human operators to work on those with highly added value or that would be too complex/expensive to be automated. [18] [19]

Considering 3-D simulations, the design of materials, products and processes are already a common reality in the aeronautical companies. However, new technologies (called Digital Twins) will be able to simulate plant operations in real-time; monitoring machines, products and even humans. This will allow more precise analysis, tests of possible scenarios and processes optimisation in digital world before physical implementation (reducing mistakes, identifying risks, driving down machine setup times and reducing costs). [10] [17]

With the implantation of sensors - in manufacturing systems, enterprise- and customer-management systems -, there will be an unavoidable data explosion generated from many different sources. In this context, Big Data Analytics solutions will enable aircraft companies to properly treat and use data to have precise information about key aspects, relate different variables, identify patterns and predict likely future scenarios. This new acquisition will support timely decisionmaking, enable a self-learning and autonomous value chain, guarantee synergy along the supply chain, allow proactive action, increase productivity and avoid process interruptions. [6] [10] [17]

Because of the increased connectivity and use of standard communications protocols, brought by the digital revolution, the application of advanced Cybersecurity will be mandatory in the aeronautical context. Enterprises will have to place technologies to ensure data security, sophisticated access management (of machines and humans), reliable communication and protection of the IT/OT infrastructure. [10]

Another technology that is already a reality in the aeronautical environment is the additive manufacturing, such as 3-D Printing (3DP). It has been used in the fabrication of prototypes, tooling and even parts to compose the airplane. Companies are now investing in Research \& Development to assure reliability on 3DP products, so that they can benefit from the production of complex shapes parts, in a short time, with different types of materials (sometimes combining them), reducing the part weight and waste of raw material. [6] [10] [17]

Finally, a popular solution that is already being applied to industrial applications (and has been improved in terms of precision, reliability and scanning) is the Augmented Reality. This versatile tool may help aircraft assembly lines in: providing work instructions in mobile devices (as previously mentioned), indicating parts in a warehouse, provide realtime information to support decision-making and train employees. [8] [10] [17]

From the description above, it might be tempting for the aircraft companies to apply some of those solutions to their organisations. However, pushing new technologies does not necessarily bring results and can even be risky (in terms of financial losses, under-exploitations of solutions, damages to IT/OT infrastructure, conflicts of previous and new IT/OT, difficulty in staff adaptation etc.). [20] Considering that, it is essential that companies have a clear vision of how I4.0 is projected to its specific context, understand its actual reality, align I4.0 deployment goals with the corporate strategy, identify the solutions that best fit their needs, plan realistic projects and manage its progress to achieve the desired results. With this mission, the present work intends to propose a complete method to guide companies in this endeavor.

\section{Analysis of the literature MII4.0}

Initially, in order to identify opportunities in the elaboration of a new method, an exploratory research on MII4.0 proposed by other authors was structured.

There were searched publications in the databases: Scielo, IEEE Xplore, Conference on Manufacturing Systems, Internet of Things World Forum, ABEPRO, Portal Capes, Simpósio de Eng. de Produção and Google Scholar. The period considered was from 2014 to 06/2018. The used keyword were (in English and Portuguese): Method, Model, Guideline, Roadmap, Deployment, Maturity Model and Steps combined with Industry 4.0, Advanced Manufacturing and Digital Manufacturing. As a result, nine publications were found (ordered by date and alphabetically): Cabral et al. [21]; Cordeiro et al. [22]; Pessl et al. [4]; Schuh et al. (ACATECH) [1]; Erol et al. [23]; Ganzarain e Errasti [24]; Geissbauer et al. (PwC) [13]; Bechtold et al. (Capgemini) [25]; Rockwell Automation [2].

Subsequently, these methods were studied, analysed comparatively and evaluated based on the good practices identified in this work (understood as those not common to all methods, but that make the deployment process more grounded in data, less subjective and more customised to the reality of each company).

Still within those good practices, there were highlighted some best practices that presented prominent points within the analysed criteria. Good and best practices are described as follows:

Projection of Vision 4.0: this criterion intended to verify if the methods presented a phase to create a Vision 4.0 in order to ensure the leveling of knowledge (among all those 
involved in the implementation process) about the concept of I4.0. Pessl et al. [4] define a detailed step for understanding the concepts of I4.0, while Erol et al. [23], Ganzarain and Errasti [24] and Bechtold et al. [25] go a step further and emphasise the need to bring this vision into the specific context of the organisation (Customised Vision) - although they do not systematise a procedure for that.

Self-assessment: the self-assessment is an important step where the organisation identifies its current maturity position and stablishes a realistic basis for its decision-making process. Although this step is present in almost all methods, Schuh et al. [1] and Pessl et al. [4] stand out for establishing a logical procedure, where the current status is calculated from a multiple choice questionnaire.

Strategy definition: a phase to define the strategy of the implementation project, ensuring that the project goal is aligned with the objectives of the company. Another emphasis is given to Schuh et al. [1] and Pessl et al. [4], since those authors present a procedure (based on the calculation of current maturity stage) where the goals are set and represented by numerical levels to be reached with the evolution of the current levels.

Definition of 4.0 solutions: there is a need for a step that systematises the selection of 4.0 solutions to achieve the defined goals. Ganzarain and Errasti [24] were the only authors to mention this step; however, none of the methods has detailed this step, which is why no best practice was identified.

Evaluation of results: to collect and evaluate the achieved results, in order to evidence gains and / or losses of the project. Schuh et al. [1] emphasise in their work the need for the application of quantitative indicators for the monitoring and evaluation of the results obtained with the implementation of I4.0.

Gradual deployment: this aspect verifies if the method allows the gradual implementation of Industry 4.0. Although most methods allow this type of implementation, the method of Bechtold et al. [25] stands out for having a logical and clear cyclical structure, which visually highlight the need for continuous and incremental I4.0 deployment.

Real application: to check if the methods have already been applied in a real environment, in order to validate it. Few authors presented this differential and specially Schuh et al. [1] and Pessl et al. [4] have evidenced the applicability of the method with examples from Harting AG \& Co. and an unidentified Austrian company, respectively.

Levels of maturity: to verify if the authors propose a maturity scale (in order to allow the diagnosis of the current situation and the definition of the goal) and how many levels of gradation it presents. In this regard, Schuh et al. [1] presented the most complete scale (6 degrees), the only one containing the predecessor stages of Industry 4.0 (computerisation and connectivity).

Origin: to verify if the methods were originated from an Academic (A), Corporate (C) or both sources. While an academic source is distinguished for the scientific background, the second one values a more practical and applicable approach to the industrial context. Schuh et al. [1] and Cabral et al. [21] presented the best practices for having their MII4.0 elaborated from the collaboration of academic and corporate sources.

In this sense, fig. 1 summarises the comparative analysis, indicating the works that meet the good practices and those with the best practices (highlighted in blue).

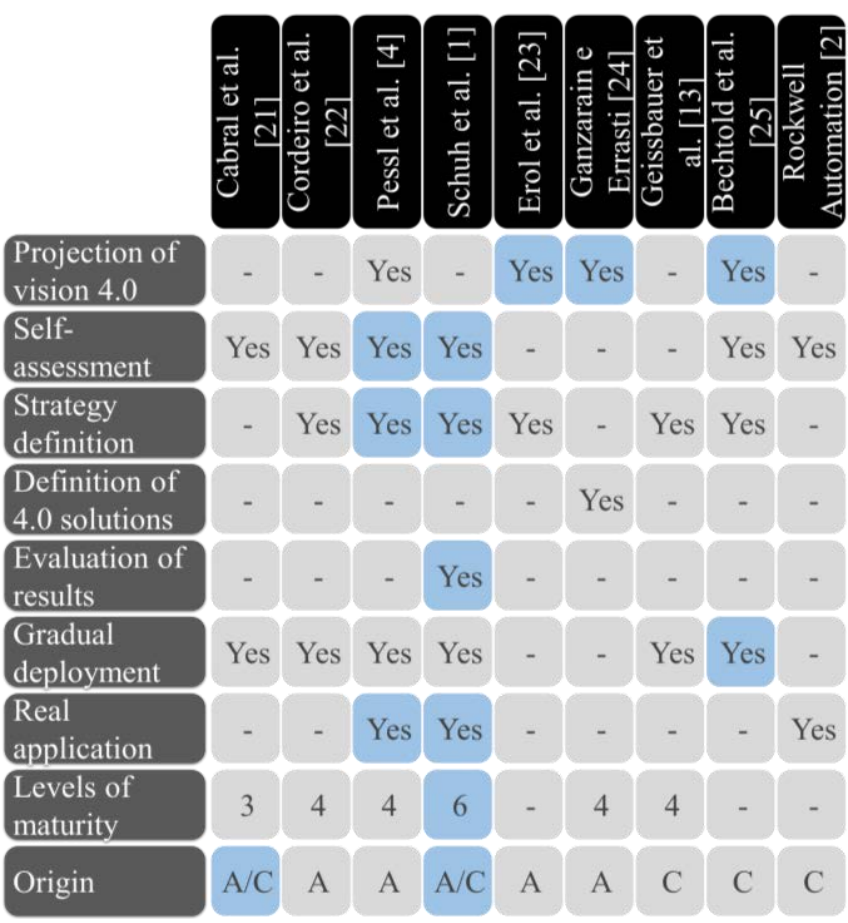

Figure 1: Comparative analysis of the MII4.0 of the literature

Through this analysis, it was concluded that none of the methods meet all the identified best practices, evidencing an opportunity to create a more complete method. In addition, the combination of these best practices allowed the creation of an ideal model that would serve as a reference for the proposal of this work, which is presented in the following section.

\section{Proposal of a MII4.0 and representation in the Aircraft Final Assembly}

Based on the previous analysis and the information collected from the literature, the 8-step method was proposed and represented as in fig. 2 .

As shown, the method was strategically built over the PDCA structure, due to the three motivations: (1) it is widely known in the market, generating greater receptivity among users; (2) it summarises the basic concepts of management, facilitating the understanding of the sequential logic of the method; and (3) it has a cyclical representation, inducing the culture that the implementation of Industry 4.0 should occur progressively since, as observed by Schuh et al. [1] and Chukwuekwe et al. [6], a systemic and robust transition must be made in a gradual way, respecting the organisational structure. 


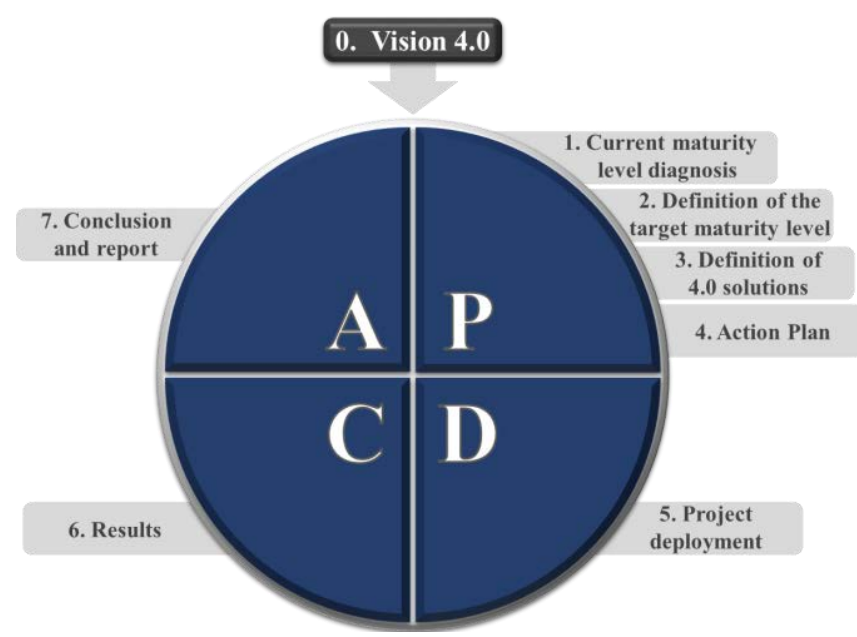

Figure 2: Proposed MII4.0

In this way, each of the stages is described in the following topics and then exemplified by a representation performed in the Aircraft Final Assembly scenario. It is important to emphasise that this representation was made based on the literature study and through interviews conducted with 22 professionals from this area. In addition, the data used is from a fictional example, without referring to any specific company, due to confidentiality issues.

\subsection{Vision 4.0}

Considered the most important step of the method, it represents the formalisation of the Industry 4.0 concept, specifically translated to the context where the method will be deployed - which is achieved through a customised maturity scale.

The I4.0 maturity scale can be understood as a reference metric that guides the company in its classification regarding the different levels of deepening in this universe. [4]

For the construction of the customised maturity scale, the present work developed an innovative procedure based on three dimensions: Internal, Structural and Conceptual 4.0 according to fig. 3. They are explained and exemplified in the Aircraft Final Assembly context, as it follows.

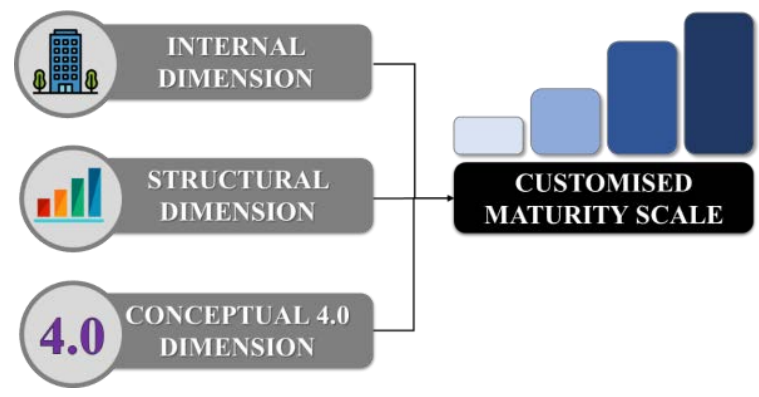

Figure 3: Dimensions used in the construction of the Customised Maturity Scale

The Internal Dimension refers to the nature of activities that are present in the company/areas and is responsible for the characterisation of the maturity scale to the specific context of the company.
The nature of activities list is obtained from the macro process mapping, exemplified in four steps in fig. 4, for the Aircraft Final Assembly context.

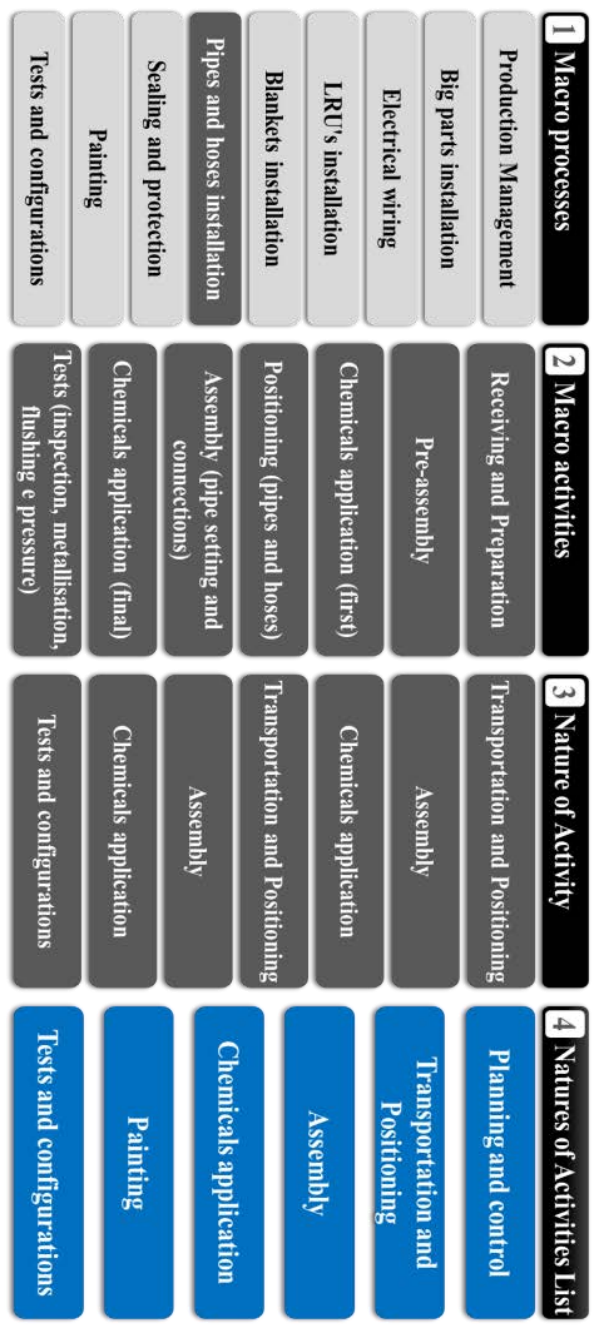

Figure 4: Procedure for the identification of the Activity Nature List (Internal Dimension)

(1) Macro processes are mapped - in fig. 4, nine macro processes were mapped in the Aircraft Final Assembly.

(2) Macro activities from each macro process must be identified - in fig. 4, the "Pipes and hoses installation" macro process was explored as an example.

(3) Macro activities with similar characteristics are grouped - forming "Nature of Activity" clusters.

(4) All the different "Natures of Activities" clusters are identified and listed - for the Aircraft Final Assembly context, the six clusters indicated in blue were identified. These clusters represent the internal dimension and shall be projected on the customised maturity scale.

Note: the full macro process mapping and the Internal Dimension definition for a general Aircraft Final Assembly area is presented in the Attachment 1.

The Structural Dimension corresponds to the structure of the maturity scale itself (number of levels, nomenclatures and main characteristics of each level). 
It consists of a generic maturity scale and can be obtained from the literature (developed by other authors) or conceived by specialists of the company (able to build one).

It is suggested in this work the use of the structure of the ACATECH maturity scale [1] - fig. 5, since it summarises concepts of I4.0 that are frequently cited in the literature, has a logical transition between levels and is the most complete amongst the authors studied in this work (6 maturity stages).

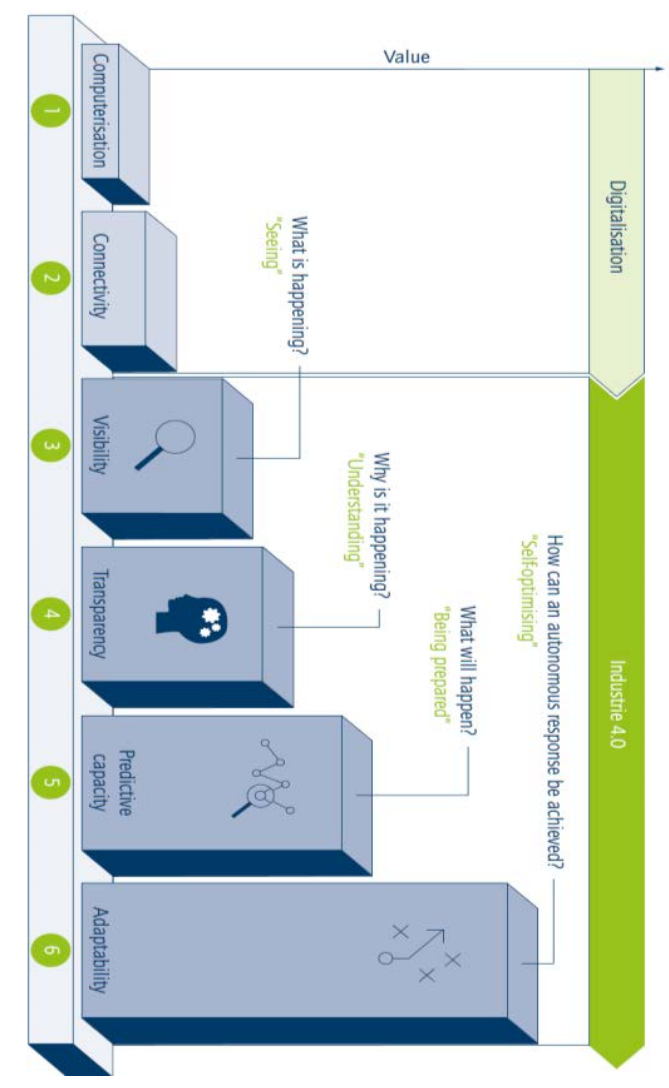

Figure 5: ACATECH maturity scale [1]

In this scale, the authors classify the first two levels (Digitalisation) as a prerequisite for entry into Industry 4.0. Thus, level (1) Computerisation represents the stage where the company starts to use automated and disconnected equipment. At level (2) Connectivity, automated equipment is connected, with automatic data and information traffic. In level (3) Visibility, in addition to previous levels, the company has monitoring sensors throughout the process, capable of providing real-time data on production status. In level (4) Transparency, the organisation acquires intelligent manufacturing systems, able to relate different data and identify the probable causes for different behaviours of the process. In level (5) Predictive Capacity, IT systems are able, based on current and historical data, to predict likely future scenarios, assisting in the preventive decision-making. Finally, in level (6) Adaptability, the manufacturing systems acquire the intelligence to make decisions and act autonomously in predefined situations to optimise the production process, without human interference.

Finally, Conceptual 4.0 Dimension consists of the Industry 4.0 technologies and systems that are applicable to the processes of the organisation.
For this purpose, the company should work on researches, benchmarking, contact with commercial representatives etc. Examples of 4.0 terms: Big-Data, Additive Manufacturing, Cloud Computing, Internet of Things, Augmented Reality etc. (More examples are given in Section 2.1).

With the three dimensions identified, the natures of activities (Internal Dimension) have to be individually described according to the characteristics it should present in each of the different levels of maturity (Structural Dimension). Furthermore, the I4.0 terms (Conceptual 4.0 Dimension) should complement the descriptions, detailing the characteristics of the maturity stage to which they belong.

Figure 6 represents one of the lines of the Aircraft Final Assembly maturity scale (related to the Transport and Positioning cluster), in order to exemplify it.

Note: the full Aircraft Final Assembly maturity scale (created based on [1] [6] [8] [10] [14] [17] [18] [19]) is presented in the Attachment 2.

\subsection{Current maturity level diagnosis}

Based on the customised maturity scale, the company should classify each of its macro activities (already mapped in the first stage) in one of the maturity levels (1-6), according to the characteristics of the cluster to which they belong.

At the end, the grades are summarised in a table, indicating the number (No) of macro activities classified on each level within each Nature of Activity cluster. Thus, the resulted Maturity Level (ML) of each cluster (column) is given by the weighted average of the grades as indicated in eq. (1) adapted from [1] [4]. A theoretical example is given in tab. 1.

$$
\begin{gathered}
(\text { No of macroactivities level } 1) \times 1+ \\
(\text { No of macroactivities level } 2) \times 2+ \\
(. . .)+
\end{gathered}
$$$$
\boldsymbol{M L}_{\text {cluster }}=\frac{(\text { No of macroactivities level } 6) \times 6}{\text { Total No of macroactivities }}
$$

\begin{tabular}{|c|c|c|c|c|c|c|c|}
\hline Classification & 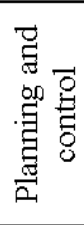 & 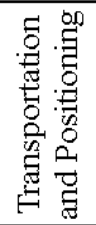 & 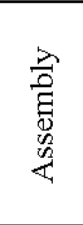 & 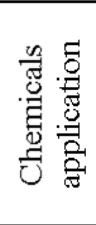 & 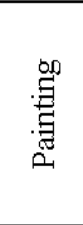 & 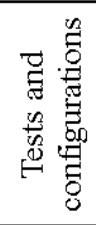 & 离 \\
\hline 0 & 0 & 5 & 0 & 0 & 0 & 0 & \\
\hline Level 1 & 1 & 1 & 1 & 1 & 0 & 1 & \\
\hline Level 2 & 2 & 8 & 4 & 2 & 1 & 2 & \\
\hline Level 3 & 2 & 1 & 3 & 1 & 1 & 5 & \\
\hline Level 4 & 0 & 0 & 0 & 0 & 0 & 0 & \\
\hline Level 5 & 0 & 0 & 0 & 0 & 0 & 0 & \\
\hline Level 6 & 0 & 0 & 0 & 0 & 0 & 0 & \\
\hline $\begin{array}{c}\text { Current } \\
\text { Maturity Level }\end{array}$ & 2.20 & 1.33 & 2.25 & 2.00 & 2.50 & 2.50 & 2.13 \\
\hline
\end{tabular}

Table 1: Current Maturity Level diagnosis table.

As shown in tab. 1, from fifteen macro activities of the Transportation and Positioning cluster, five were below level 
1 (then, they were classified at level 0), one was at level 1, eight were classified at level 2 and one was classified at level 3. From the eq. (1), the resulted current ML for this cluster was 1.33. This procedure was made for all the clusters, resulting in the global current ML (2.13), which is given by the arithmetical average of the clusters.

\section{TRANSPORTATION AND POSITIONING}

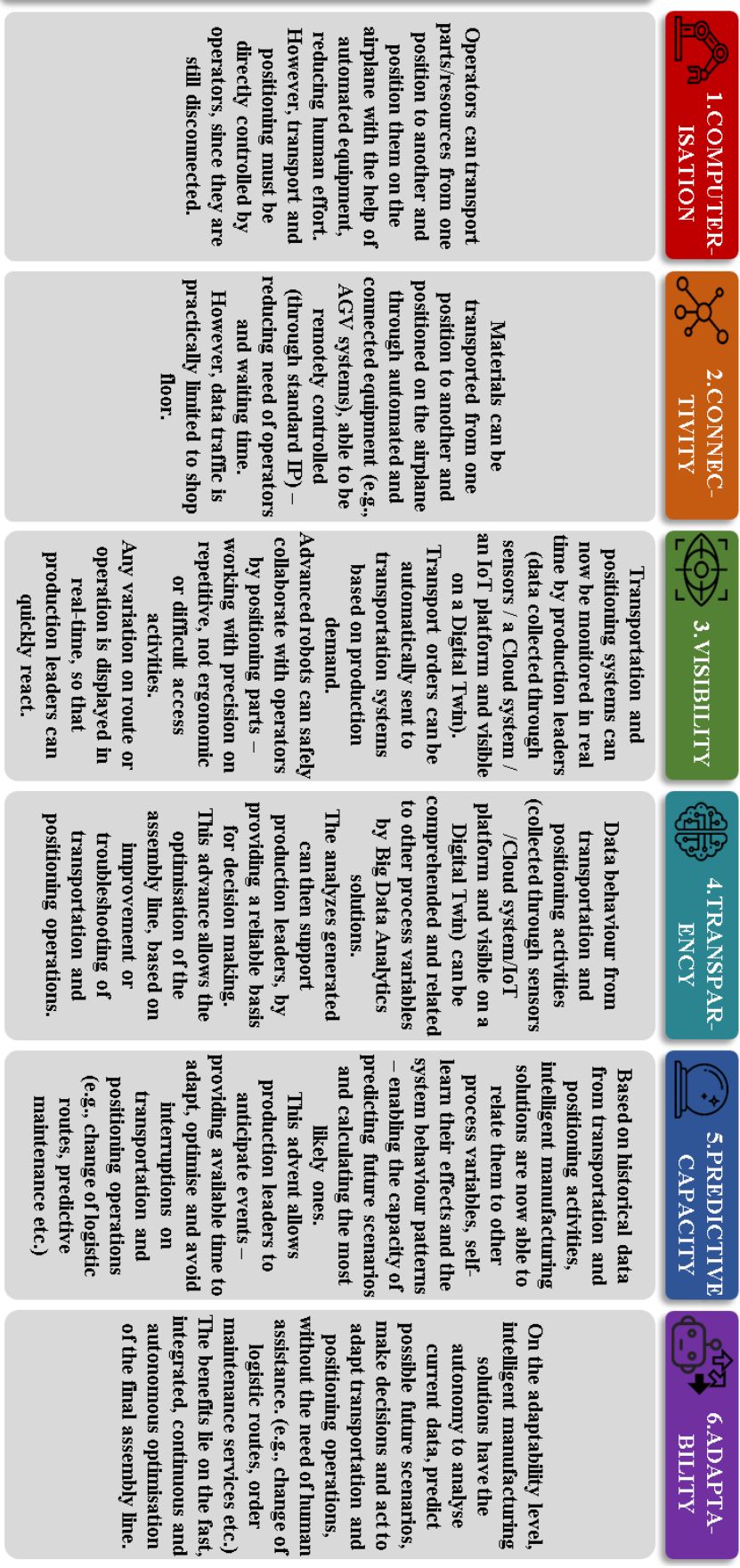

Figure 6: Maturity levels for the Transportation and Positioning cluster

Note: in this example, it was considered that all clusters had the same degree of importance, so a simple arithmetical average was used for the global ML. If, in another context, a company consider the clusters to have different degrees of importance, a weighted arithmetic average can be used.

\subsection{Definition of the target maturity level}

After calculating its current ML, the company is able to set a goal of progress on the Industry 4.0 path. This definition should involve the managers of the related areas and take into account: the area / company strategy, the current ML and the customised maturity scale (which provides future state projections as a benchmark). [1] [4]

In defining its goal, the company must formalise it by means of a table similar to the Current Maturity Level diagnosis table. Thus, in the example of tab. 2, the company chose to increase the ML of the Transportation and Positioning cluster, migrating four positioning macro activities from level 0 to level 3. As a result, the Target ML of this cluster was set to 2.13 (being elevated from 1.33) and for the Final Assembly area (as a whole), it was set to 2.26 (moving from 2.13).

Table 2: Target Maturity Level definition table.

\begin{tabular}{|c|c|c|c|c|c|c|c|}
\hline Classification & 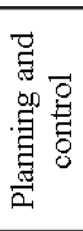 & 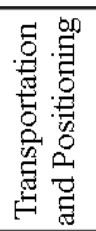 & $\begin{array}{l}\frac{2}{0} \\
\frac{0}{0} \\
0 \\
0 \\
0 \\
0\end{array}$ & 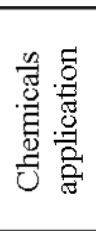 & 睍 & 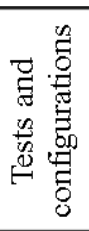 & 党 \\
\hline 0 & 0 & 1 & 0 & 0 & 0 & 0 & \\
\hline Level 1 & 1 & 1 & 1 & 1 & 0 & 1 & \\
\hline Level 2 & 2 & 8 & 4 & 2 & 1 & 2 & \\
\hline Level 3 & 2 & 5 & 3 & 1 & 1 & 5 & \\
\hline Level 4 & 0 & 0 & 0 & 0 & 0 & 0 & \\
\hline Level 5 & 0 & 0 & 0 & 0 & 0 & 0 & \\
\hline Level 6 & 0 & 0 & 0 & 0 & 0 & 0 & \\
\hline $\begin{array}{c}\text { Target } \\
\text { Maturity Level }\end{array}$ & 2.20 & 2.13 & 2.25 & 2.00 & 2.50 & 2.50 & 2.26 \\
\hline
\end{tabular}

\subsection{Definition of 4.0 solutions}

From the goal definition, the company must then identify the 4.0 solutions that will allow its achievement.

This procedure occurs in three stages: (1) initially, the company conducts a market research for possible solutions; (2) these solutions are filtered through mandatory requirements (local legislation, mandatory process requirements, internal standards etc.); (3) Finally, candidate solutions that meet the mandatory requirements should be evaluated through a Decision Making Method (DMM).

For the example used in this work, the progress of the ML of the positioning macro activities was simulated, using collaborative robotics solutions (ensemble with the systems required for their integration with the company IT/OT infrastructure, allowing them to be digitally visible and interact with other systems/humans in the company).

Thus, as represented in fig. 7, an initial research resulted in 15 available solutions, which were filtered by requirements of payload, system weight and standard Protocol. As a result, five candidate solutions were selected to be evaluated through a Decision Making Method (DMM). Although the proposed MII4.0 does not delineate which one shall be used, it is suggested the use of AHP, due to its high versatility, the 
possibility of using qualitative / quantitative variables and ease of application.

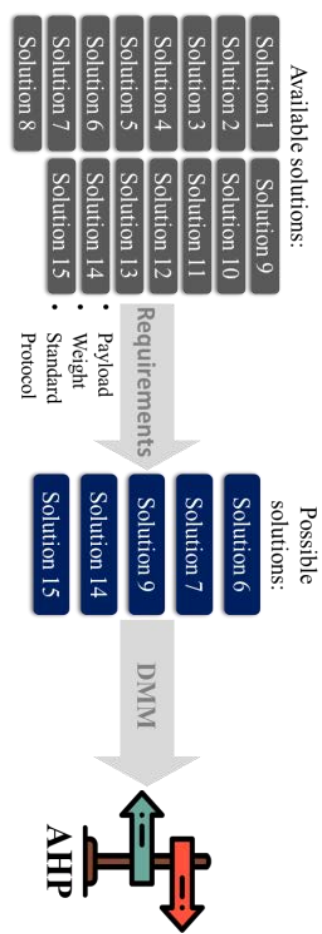

Figure 7: Procedure for the definition of 4.0 solutions

At the end of the decision-making analysis, the company is able to compare the evaluation grade and the cost of each solution, so that the most suitable one(s) can be selected for implementation. Note: the simulated solutions had their details hidden for brand exposure reasons.

\subsection{Action plan}

Similar to the same name step of the traditional PDCA tool, in this stage the actions required for the implementation of the selected solution(s) are identified and formalised.

It is important to notice that before the solution implementation itself, several predecessor actions might be required in order to enable the proper integration with the company IT/OT infrastructure.

According to Andrade [26], this step is the product resulted from all the activities contained in the $\mathrm{P}$ phase (Plan) and must be detailed in order to achieve the goal. This detailing can be done through the $5 \mathrm{~W} 1 \mathrm{H}$ : What, When, Who, Where, Why and How.

Note: because this work describes a representation (and not a real application), this and the following steps do not have a content for the Aircraft Final Assembly example.

\subsection{Results}

At the end of the project deployment, the company must collect and analyse the results in terms of two aspects:

Project - verify if the deployment was within the defined scope, finished on time and did not exceed the budget.

Goal - confirm if the target maturity level was achieved.
This information should then be registered and serve as input for the conclusion of the project, in the last step.

\subsection{Conclusion and report}

Finally, the achievement of all expected results in terms of project and goal, indicates the success of the project. In this case, the company should: (1) disseminate the results obtained, (2) record the lessons learnt, (3) formalise the new process and (4) monitor the new process indicators to ensure robustness.

The non-achievement of at least one of the expected results represents a failure (partial or complete) of the project. In this case, the responsible team should: (1) carry out a cause analysis, (2) decide on correction (through a new action plan) or project disruption, (3) execute the decision and (4) register the lessons learnt, so as not to make the same mistakes on future projects.

Finally, the conclusion indicates a new iteration of the cycle, following the philosophy of continuous improvement.

Note: the full method summary flowchart is detailed in the Attachment 3.

\section{Evaluation of the proposed MII4.0}

The proposed method was evaluated in two ways: (A) comparative evaluation and (B) value perception research.

(A) By comparative evaluation, the proposed MII4.0 was compared with the work of other authors through the nine best practices identified in the literature, as represented in fig. 8 .

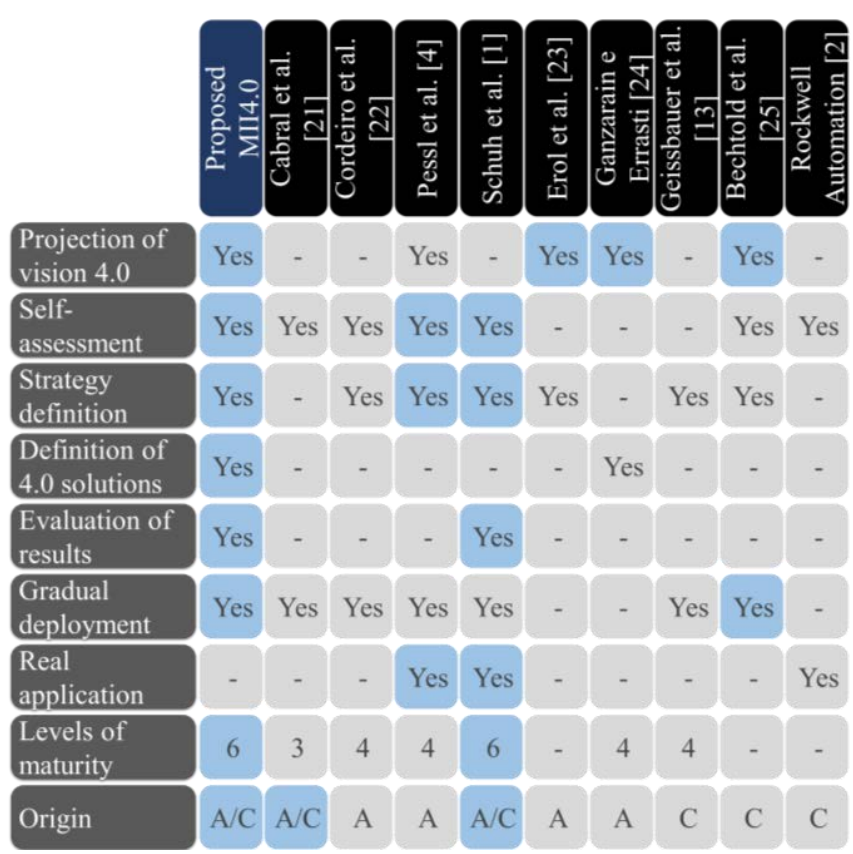

Figure 8: Comparative evaluation of the proposed MII4.0

It was verified that the proposed MII4.0 has 8 of the 9 best practices analysed, being the most complete one:

- It has a Vision 4.0 stage with an innovative procedure for the construction of a customised maturity scale; 
- It systematises a procedure to diagnose the current maturity level of companies - adapted from [1] and [4];

- It has a stage to define the target maturity level, based on the company's internal strategy, current maturity level and the built customised maturity scale - adapted from [1] and [4];

- It introduces (in an innovative way among the existing MII4.0) a systematised procedure to define 4.0 solutions;

- It presents a stage for the collection and analysis of the project results;

- It has a cyclical structure to induce the gradual implementation of I4.0 - based on the PDCA tool;

- It has its deployment based on a six-levels maturity scale (comprising the two prerequisite steps for the I4.0 deployment - presented by ACATECH [1])

- It was built from an academic work and corporate contributions (feedback from professionals from industry, after the method was simulated and presented).

- The negative aspect raised by this analysis concerns the application of the method in a real environment. If this criterion had been met, a more concrete evaluation about the method quality would be possible. However, it was not possible to do so within the term of this work, due to corporate unavailability. Nevertheless, the present work is an initial study towards a field that is yet little explored and, as such, it is understood that the knowledge generated here may contribute to future implementations or even later works.

(B) For the perception survey, thirty-three interviewees were selected based on their experience and expertise in innovation projects in the aeronautical industry - considering they had to be qualified enough to evaluate the applicability of the proposed method.

From this group, four people worked on Research and Development of New Technologies, being responsible for searching market-incoming technologies (from low Technology-Readiness-Levels, TRL) and developing them, until they are ready to be applied in the industrial environment. Those professionals had an average of 18.6 years of experience in the aircraft industry.

Three other respondents were specialists in Manufacturing Digital Solutions, with an average of 27.7 years of experience in the implementation of CAD (Computer Aided Design), CAE (Computer Aided Engineering), CAM (Computer Aided Manufacturing), MES (Manufacturing Execution System), PLM (Product Lifecycle Management), SPDM (Simulation Process \& Data Management) and systems integration in the aviation sector.

Moreover, three participants worked on the Manufacturing Strategy department, responsible for coordinating processes, methods, indicators and resources, ensuring the competitiveness of the manufacturing sector. This group counted with an average of 13.7 years of experience in the aeronautics field.
The greater group (twenty respondents with an average of 12.6 years of experience) were from the Final Assembly area, working directly with the application of manufacturing technologies in the productive process.

Finally, the last three interviewees came from the academic area. Two of them were PhD's in Aeronautical and Mechanical Engineering (working as professors and researchers in the manufacturing field) and one was MSc. in Aeronautical and Mechanical Engineering (working as a researcher in the manufacturing field).

In this sense, the proposed MII4.0 was presented to all participants, who evaluated it in six aspects:

- If it was relevant (for the industrial and literature field), fig. 9 - item evaluated by unanimity $(100 \%)$ as very relevant or relevant, evidencing the importance of the theme explored in this work.

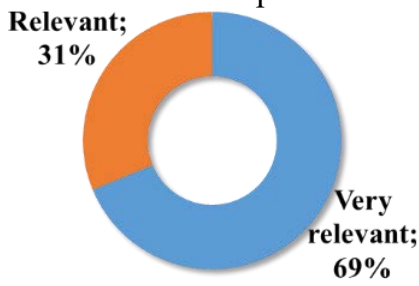

Figure 9: perception survey - relevance of the method

- If it was visually friendly, fig. 10 - receiving a very positive or positive perception by $97 \%$ of the respondents ( $3 \%$ in the neutral zone), which is probably due to its structuring according to the PDCA tool, which generates greater familiarity, understanding and acceptance on the part of users.

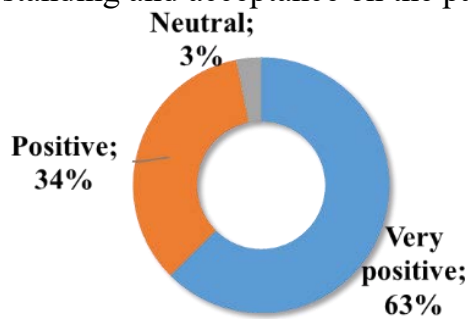

Figure 10: perception survey - visual friendliness

- If it had a logical structure, fig. 11 - also understood by unanimity $(100 \%)$ as very positive or positive, indicating that the interviewees were able to assimilate the logic of the stages of the customised model and the way in which it leads to the proposed objective. Again, the use of the PDCA method may have contributed in this aspect, by guiding the steps according to the fundamentals of management.

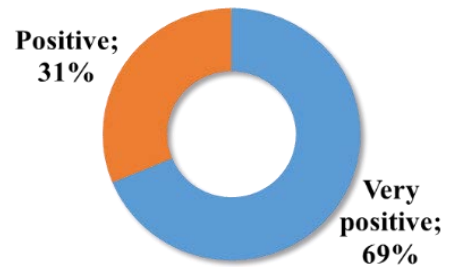

Figure 11: perception survey - logic of the proposed structure 
- If it was complete (i.e., it did not lack any relevant step for a project of this nature), fig. $12-$ in this question, all the interviewees classified the method as complete or had the main steps, without pointing out any missing steps.

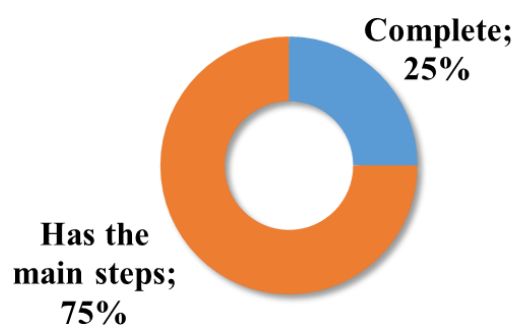

Figure 12: perception survey-completeness of the proposed method

- If it was practical, fig. $13-91 \%$ of the respondents considered it to be practical or very practical, $6 \%$ neutral and 3\% complex. The criticisms were based on the diagnosis (which was previously done by questionnaire as proposed by [1] and [4]). As a solution, it was simplified to a direct classification of the mapped macro activities by nature of activity clusters in the maturity scale, without the need for questionnaires, allowing a complete, practical and yet representative evaluation.

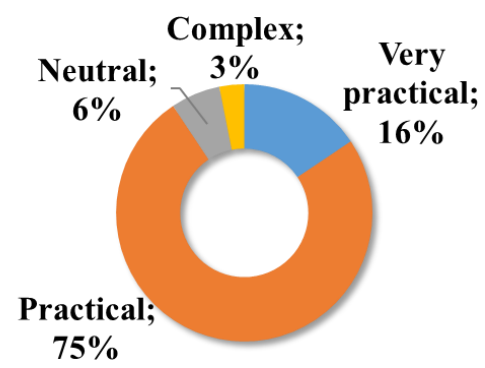

Figure 13: perception survey-practicality of the proposed MII4.0

- If it was versatile (that is, applicable to different industrial contexts), fig. 14 - in the last topic, $97 \%$ of respondents pointed the MII4.0 as very versatile or versatile and $3 \%$ as neutral (due to doubt of the robustness of the proposed method, that should be applied on a real context to be confirmed). This evaluation is very favourable to the elaborated MII4.0, indicating its potential of application in companies and areas of different sectors, even for very specific business as the aircraft industry.

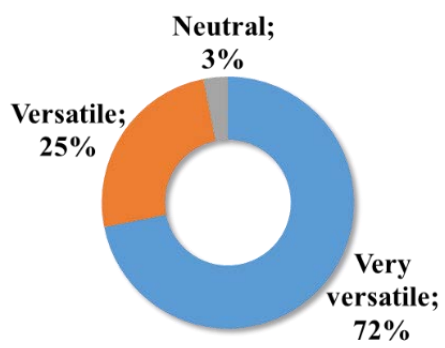

Figure 14: perception survey - versatility of the method

\section{Results and conclusions}

From the previous study, it is concluded that the main objective of this work was reached, with the proposal of a method based on the best practices identified in the literature and based on a customised I4.0 maturity scale, so that it could be applied to specific contexts (as the aeronautical industry).

In addition, the work had the following results:

- Presented a comparative analysis of nine methods in the literature, through nine good practices identified;

- Developed a more complete method, among those analysed - presenting 8 of the 9 best practices identified;

- Created an innovative procedure for creating the customised maturity scale;

- Carried out the mapping of macro processes and macro activities of a general Aircraft Final Assembly context;

- Elaborated a customised maturity scale for the Aircraft Final Assembly context.

Finally, the evaluations by comparative analysis and perception survey presented very favourable results to the method, indicating its applicability potential and its value of contribution in the industrial and academic field.

\section{References}

[1] G. Schuh, R. Anderl, J. Gausemeier, M. T. Hompe, W. Wahlster, Industrie 4.0 Maturity Index. Managing the Digital Transformation of Companies, Munich: Herbert Utz. Acatech study, 2017.

[2] Rockwell Automation, "The Connected Enterprise Maturity Model”, 2014. [Online]. Available: http://literature.rockwellautomation.com/idc/groups/ literature/documents/wp/cie-wp002_-en-p.pdf. [Accessed 10-05-2018].

[3] M. E. Porter, J. E. Heppelmann, "How Smart, Connected Products are Transforming Competition", Harvard Business Review, 2015.

[4] E. Pessl, S. R. Sorko, B. Mayer, "Roadmap Industry 4.0 - Implementation Guideline for Enterprises. International Journal of Science", Technology and Society, vol. 5, nr. 6, pp. 193, 2017.

[5] M. Damm, Fraunhofer, "Industrie 4.0 - an overview", 2017. [Online] Available: https://www.ipa.go.jp/sec/old/users/seminar/seminar yokohama_20170227-03.pdf. [Accessed 18-022019]

[6] D. O. Chukwuekwe, P. Schjolberg, H. Rodseth, A. Stuber, "Reliable, Robust and Resilient Systems: Towards Development of a Predictive Maintenance Concept within the Industry 4.0 Environment", EFNMS Euro Maintenance Conference, 2016. 
[7] G. F. Barbosa, “Aplicação da metodologia DFMA Design for Manufacturing and Assembly - no projeto e fabricação de aeronaves", São Carlos, 165 p., Masters dissertation, Universidade de São Paulo, 2007.

[8] European Comission, "Industry 4.0 in Aeronautics: IoT applications", 2017. [Online] Available: https://ec.europa.eu/growth/toolsdatabases/dem/monitor/sites/default/files/DTM_Aer onautics\%20-\%20IoT\%20Applications\%20v1.pdf. [Accessed: 14-09-2019]

[9] I. Colotla, I.; A. Fæste, A. Heidemann, A.Winther, P. H. Andersen; T. Duvold, M. Hansen, Winning the Industry 4.0 race. How ready are Danish manufacturers?, Copenhagen: Boston Consulting Group \& Innovationsfonden, 2016.

[10] M. Rüßmann; M. Lorenz, P. Gerbert, M. Waldner, J. Justus, P. Engel, M. Harnisch, " Industry 4.0: the future of productivity and growth in manufacturing industries", Boston Consulting Group, vol. 9, nr. 1, pp. 54-89, Apr. 2015.

[11] R. C. Schläpfer, M. Koch, P. Merkofer, Industry 4.0: challenges and solutions for the digital transformation and use of exponential technologies, Zurich: Deloitte, 2015.

[12] J. Bloem, M. V. Doorn, S. Duivestein, D. Excoffier, R. Maas, E. V. Ommeren, The fourth industrial revolution - things to tighten the link between IT and OT, Sogeti VINT, 2014.

[13] R. Geissbauer, J. Vedso, S. Schrauf, "Industry 4.0: Building the digital enterprise", 2016. [Online]. Available: https://www.pwc.com/gx/en/industries/industries4.0/landing-page/industry-4.0-building-your-digitalenterprise-april-2016.pdf. [Accessed 16-05-2018].

[14] I. Guyon, R. Amine, S. Tamayo, F. Fontane, "Analysis of the opportunities of industry 4.0 in the aeronautical sector". 10th International MultiConference on Complexity, Informatics and Cybernetics - IMCIC, 2019.

[15] G. F. Barbosa, R. V. Aroca, "Advances of Industry 4.0 concepts on aircraft construction: An Overview of Trends". Journal of Steel Structures \& Construction, DOI: 10.4172/2472-0437.1000125, vol. 3, nr. 1, 2017.

[16] M. A. K. Bahrin, M. F. Othman, N. N. Azli, M. F. Talib, "Industry 4.0: a review on industrial automation and robotic", Jurnal Teknologi, vol. 78, nr. 6-13, pp. 137-143, Jan. 2016.

[17] Deloitte, "Exponential technologies in manufacturing - Transforming the future of manufacturing through technology, talent, and the innovation ecosystem", 2018. [Online] Available: https://www.compete.org/storage/reports/exponentia 1_technologies_2018_study.pdf. [Accessed 11-092019]

[18] I. Maurtua, A. Ibarguren, J. Kildal, L. Susperregi, B. Sierra, "Human-robot collaboration in industrial applications: Safety, interaction and trust", International Journal of Advanced Robotic Systems, vol. 14, nr. 4, pp. 1-10, Dec. 2017.

[19] A. L. E. S. Vysocky, P. E. T. R. Novak, "HumanRobot Collaboration in Industry", MM Science Journal, vol. 9, nr. 2, pp. 903-906, Jun. 2016.

[20] A. Moeuf, S. Lamouri, R. Pellerin, R. Eburdy, S. Tamayo, "Industry 4.0 and the SME: a technologyfocused review of the empirical literature", 7 th IESM Conference, 2017.

[21] A. C. D. Cabral, A. N. R. Costa, C. J. Gamarra, "Micro, Pequenas e Médias Empresas a Caminho da Manufatura Avançada: uma Proposta de Roteiro", XXXVII ENEGEP, Joinville, 2017.

[22] G. A. Cordeiro, R. E. C. Ordonez, R. Ferro, P. B. Nicolela, B. C. Stella, "Etapas para Implantação da Indústria 4.0: Uma Visão Sob Aspectos Estratégicos e Operacionais", Encontro Nacional de Engenharia de Produção, Joinville, 2017.

[23] S. Erol, A. Schumacher, W. Sihn, "Strategic guidance towards Industry 4.0-a three-stage process model", International Conference on Competitive Manufacturing, pp. 495-501, 2016.

[24] J. Ganzarain, N. Errasti, "Three stage maturity model in SME's toward industry 4.0", Journal of Industrial Engineering and Management (JIEM), vol. 9, nr. 5, pp. 1119-1128, 2016.

[25] J. Bechtold, C. Lauenstein, A. Kern, L. Bernhofer, "Industry 4.0 - The Capgemini Consulting View", Capgemnini Consulting, vol. 31, Pags. 32-33, 2014.

[26] F. F. de Andrade, "O método de melhorias PDCA", São Paulo, 169 p., Masters dissertation, Universidade de São Paulo, 2003. 